\title{
As abordagens de ensino da Educação Física na formação continuada de professores da rede municipal de Santa Maria/RS
}

\author{
Physical Education teaching approaches in teachers continuous \\ training of municipal schools of Santa Maria/RS/Brazil
}

\author{
Silvester Franchi', Daiane Dalla Nora', Elciana Buffon', João Francisco Magno Ribas \\ 'Universidade Federal de Santa Maria (CEFD/UFSM), Santa Maria, RS, Brasil.
}

Recebido em: março 2015 / Aceito em: maio 2015

silvesterfranchi@hotmail.com

\section{RESUMO}

Este estudo é decorrente do projeto “Organização do trabalho pedagógico do professor de Educação Física da Rede Municipal de Santa Maria", o qual busca desenvolver um processo de formação continuada para os professores. Objetivo: analisar o entendimento dos professores sobre as abordagens de ensino da Educação Física na Formação Continuada da rede municipal de Santa Maria/RS. Método: análise documental a partir dos registros do projeto referentes às intervenções didáticas com as abordagens Desenvolvimentista, Construtivista, Crítica-emancipatória e Crítico-superadora; planilha de observação dos referidos momentos de práxis; vídeos e sistematização de cada abordagem. Resultados e considerações finais: constatou-se que os professores conseguiram estabelecer diferenças nas intervenções, porém apresentaram dificuldade em sistematizar as proposições específicas de cada abordagem. Deste modo, conclui-se a importância do trabalho com as abordagens de ensino na formação continuada para qualificar o trabalho pedagógico do professor de Educação Física.

Palavras-chave: Educação Física Escolar; Formação Continuada; Trabalho Pedagógico.

\footnotetext{
ABSTRACT

This is a study originated from the project "Pedagogical work organization of the Physical Education teacher of municipal schools of Santa Maria", which seeks to develop a process of continuous education for teachers. Objective: analyze the teachers understanding
}

of the teaching approaches of continuous education in physical education. Method: documental analysis of the project records concerning the didactic interventions with developmentalist, constructivist, emancipatory criticism and surpassing criticism approaches, observation spreadsheet of the praxis moments, and videos and systematization of each approach. Results and closing remarks: it was found that teachers were able to determine differences of each intervention, but had difficulty in systematizing specific propositions of each approach. Thereby, we observed the importance of working with continuous education approaches in order to qualify the physical education teacher pedagogical work.

Keywords: School Physical Education; Continuing Education; Pedagogical Work.

\section{INTRODUÇÃO}

As abordagens de ensino da Educação Física (EF), como a própria educação, convivem intrinsecamente em meio a conflitos epistemológicos que, se analisados em profundidade, são conflitos ideológicos em defesa da manutenção da realidade social existente ou para a transformação desta realidade. Pode-se chamar respectivamente de abordagens não críticas e abordagens críticas para o ensino de EF.

Este trabalho é decorrente do projeto “Organização do trabalho pedagógico do professor de Educação Física da Rede Municipal de Ensino de Santa Maria/ RS", desenvolvido pelo Grupo de Pesquisa em Lazer e Formação de Professores (GPELF), com a participação de professores de EF da rede municipal de ensino e, 
acadêmicos e professores da Universidade Federal de Santa Maria (UFSM).

O projeto tem como objetivo principal debater e sistematizar a organização do trabalho pedagógico do professor de EF da rede municipal de Santa Maria. Tem como objetivos específicos: elaborar um referencial teórico-metodológico para orientar o debate referente à organização do trabalho pedagógico do professor de EF no cotidiano escolar; construir dimensões lou categorias) que orientem a organização do trabalho pedagógico e da didática; sistematizar uma bibliografia básica. Com base nestes elementos: debater as orientações Curriculares do Estado do RS; sustentar e orientar teoricamente os projetos vinculados ao estudo; debater as pesquisas assim como as ações de ensino e extensão vinculadas a este projeto; realizar uma produção bibliográfica com os estudos produzidos.

Foi identificado que os professores têm dificuldades quanto ao sentido metodológico dado as suas aulas e também à compreensão e aplicação das abordagens de ensino da EF. Partindo deste contexto diagnosticado, surgiu a necessidade de compreender qual o entendimento dos professores sobre as abordagens de ensino da EF.

Dessa forma, o objetivo deste trabalho consiste em analisar o entendimento dos professores sobre as abordagens de ensino da EF, na Formação Continuada da rede municipal de Santa Maria/RS, a partir de momentos de práxis realizados nos encontros de formação.

Este estudo justifica-se pela necessidade de conhecimento aprofundado sobre as abordagens de ensino, e por ser um tema de extrema relevância para a formação continuada de professores da rede municipal de Santa Maria/RS.

\section{As abordagens de ensino da educação física}

A EF escolar torna-se obrigatória como disciplina escolar através da Lei $n^{\circ} 4024^{2}$ que estabelece a primeira Lei de Diretrizes e Bases da Educação Nacional (LDBEN) que contempla a EF no artigo 22, tornando obrigatória a $E F$, no ensino primário e médio. Porém, é através do artigo $3^{\circ}$ do Decreto 69.450 que define objetivos para os diferentes níveis de ensino da EF. Por exemplo, define que, na educação primária, as atividades devem favorecer a consolidação de hábitos higiênicos; no ensino médio o aprimoramento das potencialidades físicas, morais e psíquicas; e o ensino superior presa pela predominância do esporte. Ainda o mesmo artigo $3^{\circ}$ parágrafo $1^{\circ}$ especifica que a aptidão física é a referencia fundamental para orientar o planejamento. ${ }^{3}$

Segundo Bracht ${ }^{4}$ o corpo é estudado fundamentalmente pelo viés das ciências biológicas, em que não pensa; é pensado, analisado pela racionalidade científica. A partir destas análises restritas sobre o corpo, reflete nos objetivos que tomou a EF de "construção de corpos saudáveis e dóceis, ou melhor, com uma educação estética (da sensibilidade) que permitisse uma adequada adaptação ao processo produtivo ou a uma perspectiva política nacionalista" 4 tal como ficou claro nos primeiros objetivos impostos para a $E F$, através do anterior decreto $69.450 .^{3}$

Em sequência à dita compreensão de EF pelo viés militarista e higienista, surge a tendência de esportivização, influenciada principalmente pelo aumento do rendimento esportivo e competitividade para a produção de recordes, mudando os sentidos/significados desta disciplina em prol de preparação esportiva das novas gerações para a representação do país em âmbito internacional. ${ }^{4}$ No entanto, os pilares da EF continuam os mesmos, ou seja, de educar corpos fortes, saudáveis, ágeis privilegiando a aptidão física para o rendimento, sendo isto uma cópia irrefletida do sistema capitalista. ${ }^{5}$

Algumas perspectivas de mudança começam a surgir, apontando para uma EF com diferentes sentidos/ significados, novas objetivações. Estas novas vertentes começam a aparecer a partir do final da década de 70, quando começam a regressar ao Brasil, professores doutores que haviam saído do país para realização dos respectivos doutorados e juntamente com o início de cursos de pós-graduação. Visando não alargar aqui o debate acerca das abordagens, serão apenas apresentadas aquelas que foram utilizadas nas intervenções, juntamente com os professores.

Primeiramente, a Abordagem Desenvolvimentista, tem como principal autor Go Tani ${ }^{6}$ propondo, a partir da psicologia do desenvolvimento, os processos maturacionais inatos do crescimento, para crianças até quatorze anos. Segundo Darido, ${ }^{7}$ a especificidade da EF no contexto da abordagem desenvolvimentista é o movimento, sendo considerado o meio e o fim desta disciplina, desenvolvendo o controle e aplicação do movimento. Através desta abordagem, a adaptação ao meio é a principal finalidade da EF e o meio para atingir esta finalidade é a aprendizagem motora, tendo como conteúdos, as habilidades básicas como correr, saltar, chutar, rebater, quicar, receber. A metodologia usada é através da solução de problemas, a avaliação privilegia a habilidade, processo e observação sistemática.

A Abordagem Construtivista tem como principal autor João Batista Freire, ${ }^{8}$ com o livro Educação de Corpo Inteiro: teoria e prática da Educação Física, tem aproximações com a desenvolvimentista, pois está fundamentada na psicologia do desenvolvimento, mesmo estando preocupada com a cultura especificamente infantil. ${ }^{4}$ A finalidade da abordagem é a construção do conhecimento na cultura popular lúdica a partir de brincadeiras populares, jogo simbólico e de regras, a fim de resgatar o conhecimento do aluno, solucionando problemas.

Esta abordagem não defende claramente uma especificidade para a EF que pode ser compreendida através do eixo corpo/movimento; detêm-se na aprendizagem de conhecimentos lógico-matemáticos, deixando os conhecimentos da EF, como um meio para atingir o desenvolvimento cognitivo, como por exemplo, o movimento como facilitador da aprendizagem da escrita, leitura, matemática. ${ }^{7}$

Estas duas abordagens que foram apresentadas até o momento são consideradas pela literatura da área, como abordagens não críticas da EF, pois apresentam certas limitações, sem a intenção de apontar uma visão ampla de sociedade. No que se refere à apropriação do conhecimento pelo aluno, estas não têm uma perspectiva de transformação. A seguir apresentamos duas abordagens que sugerem metodologicamente uma visão crítica de EF, de escola e de sociedade.

A abordagem Crítico-emancipatória proposta por $K u^{9}{ }^{9}$ apresenta, através da crítica à transferência do esporte de rendimento para a EF escolar, uma transformação didático-pedagógica do esporte. Esta abor- 
dagem é fortemente influenciada por Merleau-Ponty e Paulo Freire, a partir de seus estudos desenvolvidos sobre, respectivamente, a análise fenomenológica do movimento e a pedagogia crítica. ${ }^{10}$

Kunz defende como objeto de estudo da EF a cultura de movimento, em que o movimento é compreendido de forma dialógica, em que o "se-movimentar humano" é compreendido como o meio de comunicação do sujeito com o mundo. ${ }^{4} \mathrm{~A}$ partir do desenvolvimento desta abordagem, busca-se a tomada de autonomia e participação crítica do aluno. Deste modo, o processo de ensino constitui-se em três etapas como ressalta Gonçalves"11 "a investigação temática (realização espontânea de movimentos), a problematização e crítica, e o processo de reflexão-ação, ou seja, compreender o mundo pela ação".

A abordagem Crítico-Superadora tem como principal referência o livro intitulado "Metodologia do Ensino de Educação Física". ${ }^{5}$ Esta abordagem defende como especificidade da EF a Cultura Corporal, que tem como temas os jogos, a ginástica, a dança, o esporte e as lutas. O modo como foi nomeada a presente abordagem aponta a prática pedagógica crítica para a transformação/superação da realidade social, tomando como caminho metodológico a pedagogia Histórico-Crítica de Saviani, ${ }^{12}$ a partir dos cinco passos. $1^{\circ}$ Passo, a Prática Social: significa o ponto de partida, ou seja, o conteúdo, aquilo que é comum ao professor e ao aluno; $2^{\circ}$ Passo, a Problematização, que busca identificar os principais problemas postos pela Prática Social (para a pedagogia histórico-crítica é a junção da prática inicial, com o conhecimento científico elaborado); $3^{\circ}$ Passo, Instrumentalização, faz-se necessário, proporcionar a apropriação dos instrumentos e conteúdos socialmente produzidos e culturalmente preservados, através das questões levantadas na problematização, direcionando as atividades da aula; $4^{\circ}$ Passo, a Catarse, significando a forma mais elaborada de pensamento, referente ao entendimento da Prática Social, onde os elementos culturais passam a serem elementos ativos de transformação social; (síntese-teoria/prática, cotidiano/científico); $5^{\circ}$ Passo, a Prática Social, que se refere ao ponto de chegada.

\section{MÉTODO}

Os resultados do presente estudo são alcançados através de pesquisa documental, se utilizando de materiais que ainda não foram tratados analiticamente. Segundo Sá-Silva, Almeida e Guindani, ${ }^{13}$ este tipo de pesquisa caracteriza-se como “um procedimento que se utiliza de métodos e técnicas para a compreensão e análise de documentos dos mais variados tipos", documentos estes, ainda não científicos.

Os participantes do estudo foram vinte (20) professores de EF, da rede municipal de ensino, da cidade de Santa Maria/RS. Estes participaram do projeto, através de encontros mensais realizados em uma escola da rede.

Para a realização das intervenções e debates sobre as abordagens teóricas da EF, primeiramente foram selecionadas as abordagens que mais se destacam nos âmbitos acadêmico e escolar, representados por livros que se tornaram clássicos na área. Para um debate com maior profundidade sobre as proposições de homem, mundo e prática pedagógica de cada abordagem, foi realizado um contraponto em cada encontro com uma abordagem crítica e outra não crítica, assim possibilitando aos professores uma visão mais concreta, deixando mais visíveis suas diferenças, no que se refere ao objetivo, metodologia, avaliação, etc.

As intervenções didáticas se deram a partir do desenvolvimento de aulas específicas de cada abordagem, sendo elas: Desenvolvimentista, Construtivista, Crítica-emancipatória e Crítico-superadora; planilha de observação das referidas aulas, as quais eram preenchidas a partir da observação do desenvolvimento da aula, pelo grupo de professores, em que foram abordadas as seguintes questões: tema, objetivo, relações professor/ aluno e aluno/aluno, metodologia e avaliação; vídeos como instrumento de informações de cada encontro; a sistematização de cada abordagem realizada no grande grupo, através da problematização e síntese dos principais elementos.

$\mathrm{Na}$ primeira parte de cada encontro, foram realizadas duas aulas práticas, de modo que cada aula foi abordada dentro das abordagens escolhidas para o encontro. $\mathrm{O}$ nome das abordagens que embasava a prática não era declarado aos professores. Assim, enquanto uma parte do grupo praticava a aula, a outra parte dos professores se deteve a observar e registrar na planilha de observação, a qual continha tópicos pertinentes na clarificação das abordagens.

A segunda parte do encontro foi realizada em sala de aula, onde cada uma das duas abordagens de cada encontro foi discutida, bem como os pontos contidos na planilha de observação. Ao final, juntamente com os acadêmicos e professores da UFSM, os professores de EF da rede municipal, a partir das vivências das aulas, das observações e debates em grupo sistematizaram as principais características de cada abordagem.

\section{RESULTADOS E DISCUSSÃO}

Os resultados apresentados a seguir elucidam o entendimento dos professores da rede municipal de ensino de Santa Maria sobre as abordagens Desenvolvimentista, Construtivista, Crítico-Emancipatória, Crítico-Superadora do ensino da Educação Física.

A primeira intervenção realizada junto aos professores foi realizada a partir da abordagem desenvolvimentista. O conteúdo da "aula" foi o saque por baixo do voleibol, com o objetivo de desenvolver a técnica e a precisão no saque por baixo; desenvolver o processo de tomada de decisão no saque por baixo, a partir da leitura dos espaços de jogo. A sistematização da intervenção ocorreu em quatro momentos: aquecimento; desenvolvimento (Apresentação dos objetivos; Exercícios de saque por baixo, enfatizando a técnica e precisão; Exercícios de saque por baixo nos espaços de jogo, enfatizando a técnica e precisão; Exercícios de saque por baixo, enfatizando a tomada de decisão); volta à calma e; avaliação (individualmente: nível de habilidade dos alunos em relação ao saque por baixo; entendimento e a ação do processo de tomada de decisão, para efetuar o saque).

Os professores reconheceram facilmente o objetivo central da aula que era aprender a técnica do saque por baixo; eles identificaram que este objetivo foi buscado 
a partir da aprendizagem da sequência de movimentos, do simples para o complexo, ditados e demonstrados como os movimentos corretos pelo professor. Um professor comentou que provavelmente com o seguimento de próximas aulas seria feita a continuação do processo de desenvolvimento empregando outros gestos, como o do saque por cima; houve o relato de ser uma atividade de repetição.

Quanto à relação professor/aluno e aluno/aluno, os professores da rede chegaram às seguintes conclusões: bastante mencionada à demonstração por parte do professor, que não deu oportunidade aos alunos dar sugestões, "ele só mandou nós fazer"; não aproximação aos conhecimentos do aluno; aluno com pouca habilidade iria apresentar bastante dificuldade; culpabilização por parte dos colegas a um com poucas habilidades; estímulo-resposta para aprendizagem da técnica, sem levar em consideração as diferenças entre os alunos; professor diretivo.

O processo metodológico mencionado além da demonstração de movimentos foi a de que, para o ensino, houve a parcialização do saque por baixo: posições das pernas, balanço do braço. Quanto à avaliação da aula, os professores ressaltaram o último momento da aula, que foi um jogo de sacar em espaços vazios do outro lado da quadra, sendo o resultado punitivo, que era o de pagar uma prenda à equipe com menos pontos.

Ao final das discussões da aula, na abordagem desenvolvimentista, ainda não havia sido comentado especificamente a abordagem utilizada, sendo problematizados com os professores os aspectos centrais. As relações feitas pelo grupo de professores foram vinculadas às abordagens tecnicista, militarista, construtivista, porém após algumas problematizações um dos professores chegou à conclusão que era a desenvolvimentista. Outro aspecto que não foi comentado é que a abordagem tem como objeto de estudo o movimento propriamente, este aspecto fica subentendido, porém não se chegando com profundidade. Também fica subentendido, no termo demonstração, o caráter de observação, que deve ocorrer como uma cópia de movimentos.

Na sequência, a aula trabalhada foi na abordagem Crítico-Emancipatória. Como na abordagem anterior o tema desta aula também foi o saque por baixo no voleibol, a qual tinha como objetivo, proporcionar a aprendizagem de diferentes movimentos e gestos do saque por baixo, a partir de experimentações, considerando as experiências dos alunos. Foram utilizados os seguintes momentos/estratégias didáticos para atingir o objetivo: encenação com experimentação a partir dos problemas que envolvem na realização do saque por baixo; problematização com diálogo entre alunos; ampliação das melhores possibilidades de realização do saque, a partir do diálogo anterior e, avaliação com reflexão entre os alunos sobre como e o que se conseguiu atingir nessa aula.

Nesta segunda intervenção os professores tiveram o consenso de que o objetivo foi de tentar passar a bola para o outro lado da quadra, de forma que o professor não instrumentalizou; somente deu a tarefa de passar a bola, sem introdução de passos a seguir. Comenta-se que, ao contrário da demonstração da aula anterior, nesta o professor problematiza o conteúdo. Através de análise do que propõe a abordagem, o ponto êxtase da discussão foi o comentário de que a aula anterior estava preocupada com o resultado, já esta nos meios para se chegar ao resultado, com ênfase na vivência do aprender a partir das possibilidades.

Um equívoco posto pelos professores foram falas que versavam sobre a interação entre alunos, ao considerar que, na primeira aula, os alunos tiveram atividades em duplas e nesta aula eles realizaram sozinhos, concluindo que na segunda não tiveram a possibilidade de realizar juntos. Porém avaliando esta conclusão dos professores, se pode dizer que foi considerado apenas o aspecto motor, a interação quanto à realização de movimentos, porém se se considera movimento e diálogo na proposta desta segunda abordagem, os alunos têm que interagirem criticamente, a partir dos problemas encontrados. Isto pode ser percebido no momento em que há a vivência; logo a problematização e, posteriormente, a volta a vivência. A avaliação na visão dos professores ocorreu através de da conversa entre os alunos, reflexionando sobre o que os alunos perceberam durante a aprendizagem.

O segundo encontro com o propósito de trabalhar as abordagens da EF iniciou-se com a intervenção sobre a abordagem Construtivista. Cabe ressaltar que para desenvolver esta aula foi solicitado, aos professores, que imaginassem que na aula anterior foi abordado como conteúdo o jogo de Amarelinha "tradicional". Aclarado este ponto, o tema da aula foi a amarelinha, com o objetivo de construir novas formas para o jogo, trabalhando as habilidades de saltar, lançar, coordenação espacial. A intervenção se dividiu em desenvolvimento, subdividido em: diálogo inicial; construção de amarelinha em grupos; vivência e, construção da amarelinha da turma; e, a final, a avaliação, com problematização da aula, gosto pelo jogo, habilidades que foram trabalhadas, como foi a construção em grupo.

Ao final da análise, o grupo caracterizou os elementos principais da abordagem e os professores exemplificaram a partir de suas práticas. Conceituaram como o objetivo da abordagem, a construção coletiva/ dialógica/interação como criação/recriação dos conteúdos, o jogo/brinquedo como conteúdo privilegiado e como desenvolvimento das habilidades/conhecimento corporal. A relação professor/alunos e aluno/aluno são entendidas como o professor ser o mediador,em que estimula a interação entre os alunos e o meio; esta relação parte do conhecimento da criança. A metodologia é desenvolvida pela proposição de desafios, pelo trabalho em/pelo grupo, em uma relação dialógica. Com relação à avaliação, a mesma se deu no processo e bem como na construção coletiva da amarelinha, é autoavaliativa e contínua do professor e do aluno.

A segunda abordagem do dia foi a Crítico-superadora. O conteúdo foi um jogo adaptado. O objetivo foi o de proporcionar aos professores um momento de reflexão a respeito do processo de organização social vigente, o modo de produção capitalista, a partir da categoria de lutas de classes. Para isso, para o desenvolvimento da aula, foram utilizados os "cinco passos de Saviani" (prática social, problematização, instrumentalização, catarse, prática social). No início do jogo, o handebol adaptado, o grupo de professores foi dividido em duas equipes, sendo que um deles possuía maior quantidade de jogadores, entretanto, a equipe "menor" tinha a oportunidade de impor uma regra, a sua livre escolha, ao jogo. Com o andamento do jogo, esta equipe coloca 
outras regras, limitando o trabalho da equipe adversária. A relação que se estabelece é a existente entre as distintas classes sociais, burguesia e trabalhadores. No jogo, a intenção é a de que os jogadores que tem suas possibilidades cerceadas pelas regras impostas pelo adversário não as aceitem mais e "ganhem" o jogo.

$\mathrm{Na}$ discussão da abordagem Crítico-superadora o grupo caracterizou a mesma, tendo como objetivo a problematização das desigualdades sociais, a reflexão e a superação do conhecimento preliminar para um conhecimento mais amplo; já, na metodologia foi destacado como tendo uma intencionalidade pedagógica problematizadora e a provisoriedade do conhecimento. Nesta abordagem, os professores tiveram dificuldades de identificá-la. Os professores caracterizaram como a temática sendo um jogo esportivo, o handebol; o meio foi o jogo, mas a questão principal foi o desequilíbrio entre as equipes; objetivo de reflexão sobre as relações do jogo; objetivo de construção de regras, porém de forma desigual, partindo de apenas um grupo, com imposição - aceitação; refletir sobre as regras predeterminadas. A partir desta afirmação dá-se a seguinte fala de um professor: "a gente já está formatado com as regras", e fazendo analogia à sociedade e suas "regras" sociais.

As discussões apontaram reflexões relacionadas a aspectos sociais, não menos importantes, mas distanciando da compreensão metodológica da abordagem. As seguintes reflexões foram consideradas mais importantes: "nós reproduzimos inconscientemente as características sociais desiguais na escola"; a sociedade aceita as imposições de poucos, se reclama, mas não se pode fazer nada, "vivemos em uma republiqueta pra nada"; de que é possível problematizar aspectos sociais a partir de conteúdos da Educação Física.

\section{CONSIDERACִÕES FINAIS}

O trabalho com as abordagens de ensino da Educação Física, na formação continuada de professores da rede municipal de Santa Maria/RS, que objetivou analisar o entendimento dos professores sobre as mesmas, foi um espaço de extrema relevância para a produção de conhecimento da área, bem como para a qualificação da formação continuada, com a discussão/problematização do trabalho pedagógico dos professores.

Constatamos que os professores tiveram dificuldades em sistematizar, conceituar, classificar, diferenciar as abordagens, mas em contrapartida, conseguiram identificar os principais pontos a partir das vivências das diferentes aulas. Percebeu-se, nos relatos dos professores, a importância de articulação entre teoria e prática das abordagens, as quais facilitaram o entendimento e possibilitaram a discussão e a caracterização de cada abordagem.

Concluímos a partir dos momentos de articulação da teoria com a prática, que foi um rico processo de discussão do trabalho pedagógico dos professores com as abordagens de ensino da Educação Física, fazendo com que os mesmos refletissem e aprimorassem conceitos, uma vez que se faz necessário o conhecimento mais aprofundado sobre as abordagens. Além disso, percebemos a necessidade de políticas educacionais que garantam efetivamente esse espaço de discussão, vivências, troca de experiências entre os professores, para a qualificação do trabalho pedagógico da Educação Física, e principalmente que garanta o processo de continuidade e de qualificação da formação.

\section{AGRADECIMENTOS}

O presente trabalho contou com apoio financeiro do Fundo de Incentivo à Extensão da Universidade Federal de Santa Maria para sua realização.

\section{REFERÊNCIAS}

1. Ribas JFM. Organização do trabalho pedagógico do professor de Educação Física da Rede Municipal de Santa Maria. CEFD/ UFSM, 2012.

2. BRASIL. Decreto 69.450, de 1 de novembro de 1971. Regulamenta o artigo 22 da Lei número 4.024, de 20 de dezembro de 1961, e alínea c do artigo 40 da Lei 5.540, de 28 de novembro de 1968 e dá outras providências. Diário Oficial [da] República Federativa do Brasil, Brasília, n. 208, p. 8826, 3 de novembro de 1971. Seção 1, pt. 1.

3. BRASIL. Lei $n^{\circ}$ 4024, de 20 de dezembro de 1961. Fixa as Diretrizes e Bases da Educação Nacional. Diário Oficial [dos] Estados Unidos [do] Brasil, Brasília, 278: 11429, 27 dez. 1961. Seção 1, pt. 1.

4. Bracht VA constituição das teorias pedagógicas da educação física. Cadernos Cedes, ano XIX, 48, 1999.

5. Coletivo de autores. Metodologia do ensino de educação física. $2^{\mathrm{a}}$ ed. São Paulo: Cortez, 2012.

6. Tani G. Educação física na pré-escola e nas quatro primeiras séries do ensino de primeiro grau: uma abordagem de desenvolvimento I. Kinesis, Santa Maria, 3, 1, 1987.

7. Darido SC. Educação Física na Escola: questões e reflexões. Rio de Janeiro: Guanabara, 2003.

8. Freire JB. Educação de Corpo Inteiro: Teoria e Prática Pedagógica da Educação Física. São Paulo: Scipione. 1989.

9. 9. Kunz E. Transformação didático-pedagógica do esporte. ljuí: Unijuí, 1994.

10. 10. Lavoura TN, Botura HML, Darido SC. Educação física escolar: conhecimentos necessários para a prática pedagógica. Revista da Educação Física/UEM, Maringá 2006; 17(2): 203-209. DOI: http://dx.doi.org/10.4025/ reveducfisv17n2p203-209.

11. Gonçalves VO. Concepções e tendências pedagógicas da educação física: contribuições e limites. Itinerarius Reflectionis, Jataí, 2005; 1(1).

12. Saviani D. Escola e democracia. São Paulo: Autores Associados, 1983.

13. Sá-Silva JR, Almeida CD, Gunidani JF. Pesquisa documental: pistas teóricas e metodológicas. Revista Brasileira de História \& Ciências Sociais, São Leopoldo 2009; 1(1). 